\title{
Patterns of publication effort in coastal biogeochemistry: a bibliometric survey (1971 to 2003)
}

\author{
Jean-Pierre Gattuso ${ }^{1, *}$, Nelly A. Dawson ${ }^{1}$, Carlos M. Duarte ${ }^{2}$, Jack J. Middelburg ${ }^{3}$ \\ ${ }^{1}$ Laboratoire d'Océanographie, CNRS-Université de Paris 6, BP 28, 06234 Villefranche-sur-Mer Cedex, France \\ ${ }^{2}$ IMEDEA (CSIC-UIB), Instituto Mediterraneo de Estudios Avanzados, C/ Miquel Marques 21, \\ 07190 Esporles (Islas Baleares), Spain \\ ${ }^{3}$ The Netherlands Institute of Ecology (NIOO-KNAW), Postbus 140, 4400 AC Yerseke, The Netherlands
}

\begin{abstract}
A bibliographic database comprising 17604 references on biogeochemistry and disturbances in coastal ecosystems was compiled for the period 1971 to 2004 from the Aquatic Science and Fisheries Abstracts and the Web of Science databases. The coastal ocean received increased attention starting in the early 1990 s, as shown by the increase in the rate of publication, both in absolute number (2-fold increase of the yearly rate) and relative to the publication rate of all disciplines (3-fold increase). The number of publications on each ecosystem type and the geographic location of study sites are not proportional to their respective surface area. By this measure, estuaries and the open continental shelf are, respectively, over- and under-investigated, and the research effort is disproportionately high in some areas (e.g. the North Atlantic Ocean and Mediterranean Sea, the subjects of $41 \%$ of the publications) and low in other areas (e.g. high-latitude coastal zones and the western Pacific). The cycling of inorganic nutrients is the biogeochemical process receiving the highest research effort (46\% of the publications). Although controversial, exchanges with the atmosphere, including $\mathrm{CO}_{2}$, have been poorly investigated, with only $1.3 \%$ of the publications. The magnitude of scientific community publishing increased 13-fold during the period of investigation, also demonstrating the growing interest in coastal biogeochemistry and disturbances. Moreover, the lists of authors have become longer, perhaps indicating research projects wider in scope. Senior authors from 137 countries contributed papers; the EU25 and the USA contributed about $1 / 3$ of the publications each. The number of publications per million inhabitants is highly correlated to the gross domestic product per inhabitant, but some countries perform better (the Scandinavian countries, Australia, New Zealand and Canada) or less well (Japan, the USA and Italy) than average. The number of citations of the publications is highly variable and indicates that barriers between disciplines still exist. At least 2 specialized journals (Estuaries and Estuarine, Coastal and Shelf Science) are among the most relevant journals, but Marine Ecology Progress Series is the single most important source of literature in the fields of coastal biogeochemistry and disturbances. This diagnostic should be useful to the research community and funding agencies to address the present imbalances in research allocation and to steer attention to geographical areas and processes that remain poorly investigated. Only then can the role of the coastal ocean on the global biogeochemical cycles and its response to climatic and anthropogenic disturbances be clarified.
\end{abstract}

KEY WORDS: Bibliometry · Coastal ecosystems · Biogeochemistry · Disturbances · Journals · Citations $\cdot$ Study sites $\cdot$ Affiliation Resale or republication not permitted without written consent of the publisher

\section{INTRODUCTION}

The coastal zone is an area where land, ocean and atmosphere actively interact through the exchange of matter and energy. The coastal ocean, operationally defined here as the marine area extending from 0 to $200 \mathrm{~m}$ depth, receives a large amount of nutrients and sediments from land, as well as nutrients from the atmosphere and the open ocean. In addition to such allochthonous sources, carbon and nutrients are also 
produced locally. These reactants are actively processed in the coastal ocean, which is sometimes described as a 'biogeochemical reactor' (Derry \& Murray 2004). By-products are either stored in sediments or exported to the open ocean, land and atmosphere. Because of the intensity of the processes involved in the cycling of elements in the coastal ocean, as well as the role of this zone as an interface between all major compartments of the biosphere, an adequate knowledge of the functioning of the coastal ocean 'biogeochemical reactor' is particularly critical to an understanding of the biogeochemical functioning of the biosphere.

It is unfortunate that there is, to our knowledge, no historical account of the comparative development of research in the coastal and open oceans. The main facts and milestones are, however, relatively easy to describe. From the first biological observations on seashore organisms by Aristotle and other Greek naturalists until the 19th century, research in the marine environment was essentially limited to the sea shores, due to limited access to ocean-going ships. The research was mostly dedicated to collections and classifications of organisms in coastal areas. These efforts were reinforced with the development of marine research stations starting on the European coastline in the mid-19th century, the first one in Ostende (Belgium) in 1844. The research on the physiology and ecology of marine organisms and on the elemental cycles then received new momentum. The first major report of a large-scale biogeochemical process in a coastal ecosystem is probably that of Darwin (1842), who described the formation of atolls by corals.

During the second half of the 19th century, major oceanographic expeditions were launched, which led to a relative decline of coastal research compared to open ocean research. This relative decline was modest until the 1950s, but it increased with the initiation of oceanographic institutions and oceanography departments and the steady launch of international programs operating on the global scale, such as the International Geophysical Year (1957 to 1958) and the Geochemical Sections Studies (1972 to 1978). Coastal research also increased, but far less.

Since the 1980s, the coastal ocean has gained increased attention because of the awareness of the heavy impact of human activities, which jeopardize the delivery of goods and services received from coastal ecosystems. The population of the near coastal zone (within $100 \mathrm{~km}$ horizontally and $100 \mathrm{~m}$ vertically of a coastline) was about $1.2 \times 10^{9}$ people in 1990 , or about $23 \%$ of the global population (Small \& Nicholls 2003), and the coastal zone concentrates an even larger share of the global wealth. The overall added-value benefits derived from coastal marine ecosystems have been estimated at $43 \%$ of the world's ecosystem services and natural capital (Costanza et al. 1997). This high economic value illustrates that humans use coastal ecosystems in many, sometimes conflicting, ways, such as navigation, nutrient regulation, fisheries, food production (aquaculture) and recreation. Reliance of humans on coastal resources started long ago, as shown by an analysis of a human showed who died about 550 to $600 \mathrm{yr}$ ago and was recovered from a North American glacier $80 \mathrm{~km}$ from the shore; $>90 \%$ of the man's dietary body protein was from marine (hence coastal) sources (Dickson et al. 2004). Increasing awareness of the large impact of anthropogenic activities on coastal ecosystems has stimulated research on these ecosystems and, particularly, on the cycling of elements. A token of this interest was the launch of national and international programs dedicated to the study of biogeochemical processes in the coastal ocean, such as the Land Ocean Interaction in the Coastal Zone (LOICZ; www.loicz.org), established as a core program of the International Geosphere Biosphere Program (IGBP) in 1993. As a result of these efforts, coastal biogeochemistry developed as a coherent research program examining the cycling of elements in coastal ecosystems, locally and globally, and its perturbation by human activities.

The aim of this paper is to examine the development and allocation of effort to the study of coastal biogeochemistry and anthropogenic disturbances. We do so through the analysis of the published literature on biogeochemistry and disturbances in coastal ecosystems between 1971 and 2003. We evaluate the development and allocation of effort through (1) the total rate of publication, as well as the rate broken down into ecosystem types and biogeochemical processes; (2) the size of the scientific community involved, the geographical distribution of the authors and the geographical distribution of the study sites; and (3) the outlets for this research, as the number of journals used and the allocation of space within these journals to papers on coastal biogeochemistry.

\section{METHODS}

A bibliographic database was compiled from 2 commercial databases: the Aquatic Science and Fisheries Abstracts (ASFA) published by Cambridge Scientific Abstracts, and the Web of Science 6.0 (WoS) published by Thomson ISI (www.isinet.com/products/citation/ wos). The bibliographic search was carried out during the period 12 to 30 January 2004 using the Internet versions of these databases. The ASFA database comprised >950 000 records at the time of analysis and covered the period 1971 to 2003 (although it comprises a 
few older references back to 1953). The WoS database comprised about 17 million references at the time of analysis and covered the period 1988 to January 2004. Analysis of chronological data was restricted to the period 1971 to 2003. References published prior to 1971 were found in the ASFA database, but the coverage was incomplete before that date. Likewise, the few references published in 2004 were not considered either.

Three searches were first carried out in order to collect references related to (1) types of coastal ecosystems, (2) biogeochemical processes and (3) anthropogenic disturbances (Table 1). The 3 groups of references returned were then pooled to produce the draft bibliographic database, which was analyzed using EndNote 7.0 for Mac OSX (Thomson ISI Researchsoft). The search strategy used with the ASFA database was slightly different because it required a different procedure to combine searches. However, the same keywords as those shown in Table 1 were used.

The draft database was then carefully scrutinized to eliminate duplicate references. Some articles were present twice with slightly different titles or with typing mistakes. For example, the Russian and English versions of articles published in Russian journals translated to English were sometimes present in the ASFA database. Also, some articles were published twice in different journals. All these duplicates were deleted. At this stage, the database comprised 10068 and 11792 references from the WoS and ASFA databases, respectively. The final number of publications, after deletion of references present in both the ASFA and WoS databases, was 17721 for the period 1953 to 2003.

Other changes were needed to make analyses of the database possible. The journal names used by the ASFA and WoS databases are not consistent, and the titles of some journals changed during the period considered. All abbreviations of journal names and typing differences were homogenized. The page numbers were not provided for 84 of the 5740 papers published by the top 27 journals. It was arbitrarily set to 2 . The number of pages published every year by the 28 journals leading in number of papers on coastal biogeochemistry published annually was obtained either from the editors or, if available, from the Internet.

Author names were homogenized as much as possible, but uncertainties remain due to incomplete indexing of first name initials by the publishers of the ASFA and WoS databases. The country of affiliation of authors (note that the AFSA database does not provide the affiliation of junior authors) was also made consistent using the most recent country list and the names of new countries using the list established by the International Organization for Standardization (www.iso.org/iso/en/prods-services/ iso3166ma/02iso-3166-code-lists/list-en1.html\#sz). The gross domestic product of these countries for the years 1998 to 2002, the only years available free of charge, was collected from the World Bank website (http://devdata. worldbank.org/data-query/) and averaged. The human population in the year 2000 is from the United Nations Population Division (http://esa.un.org/unpp/).

The keywords describing the geographical locations of the study sites provided by the ASFA database were extracted and analyzed. There are no such keywords in the WoS database, a few ASFA references do not have location keywords and several publications investigated more than 1 study site. Consequently, the geographical location of the study sites is available for only 8369 of the 17721 references published between 1953 and 2004. A total of 10321 geographical locations were found for these 8369 references. The surface area of each ASFA area was calculated using the gridded ETOPO2 data set downloaded from the Data Support Section of the National Center for Atmospheric Research (http://dss.ucar.edu/datasets/ds759.3/data/). It blends satellite altimetry with ocean soundings and new land data to provide a global elevation and bathymetry on a $2^{\prime} \times 2^{\prime}$ grid. The UNIX version of the Generic Mapping Tool (gmt 3.4.2-3), with its full resolution coastline, was used to calculate surface areas.

The various types of ecosystems and of biogeochemical processes and parameters were grouped into larger groups for the sake of clarity of the figures. The 12 following groups of ecosystems were considered: estuaries and river deltas, shelves, coastal sediments and mud flats, lagoons, coral reefs, algal beds, beaches, mangrove forests, coastal wetlands and saltmarshes, coastal upwellings, seagrass meadows and others (coastal canyons, submerged banks, polar ecosystems, shallow nearshore habitats, coastal hydrothermal vents, caves and hypersaline coasts). The 7 groups of biogeochemical processes and parameters considered are: inorganic nutrients, primary production, dissolved organic compounds, anthropogenic activities and disturbances, exchanges with the atmosphere, fluxes of calcium carbonate and others (with keywords other than those included in the previous groups).

\section{RESULTS AND DISCUSSION}

\section{Yearly rate of publication}

The number of publications in the field of coastal biogeochemistry increased greatly during the period 1971 to 2003 (Fig. 1A). The number of publications per year recovered from the ASFA database increased $>9$ times between 1971 and 2001 (88 vs. 832; or $4 \% \mathrm{yr}^{-1}$ ) 
and, for reasons that remain unclear, decreased to 672 papers in 2002. A large increase was also found with the WoS database (from 117 to 1119 between 1990 and 2002). The low return rate of relevant articles from the WoS database during the period 1988 to 1990 is likely due to the fact that few records contained an abstract. In 1988 and 1989, 100\% of the relevant records had no abstract. This figure went down to $27 \%$ in 1990 and to $3 \%$ in 1994 . Since the search strategy included the WoS topic keyword field, which also indexes the

Table 1. Search strategy used for the Web of Science database. Wildcard symbols as well as boolean operators were used to ascertain that all relevant references were collected. Duplicate records been deleted only once in the final set. 'TS' is the topic keyword which includes the article title, keywords and abstract, the wildcard characters '*' and '?' are the truncation operators for multiple or single characters, respectively. 'AND', 'OR' and 'SAME' (search of records containing both groups of keywords in the title, in the keyword field, or in the same sentence of the abstract) are the boolean operators used. The searches had to be carried out in several sets because of the limitations imposed by the interface. There is a limit (50) to the maximum number of words separated by boolean operators in a single set, and no more than 20 sets can be saved for subsequent use for combining searches

Step and no.

Keywords history

of records

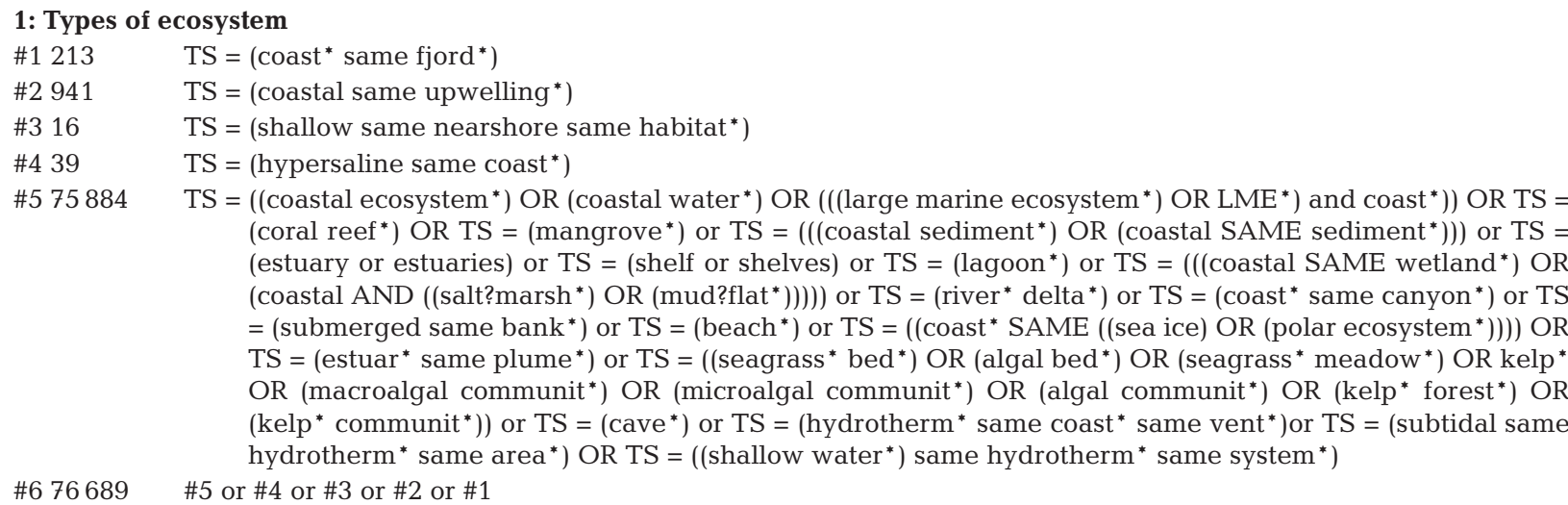

2: Biogeochemical processes

\#1 4475 TS $=\left(\right.$ biogeochemi $\left.^{*}\right)$

\#2 52 TS $=\left(\left(\left(\right.\right.\right.$ coast $^{*}$ not coastral $)$ same flux $\left.{ }^{*}\right)$ and (carbon dioxide or CO2 or pCO2) $)$

\#3 26271 TS $=\left(\left(\left(\left(\right.\right.\right.\right.$ gas $^{*}$ exchange $\left.^{*}\right)$ SAME atmosphere $)$ OR $\left(\left(\right.\right.$ global SAME $\left(\right.$ warming OR change $\left.\left.{ }^{*}\right)\right)$ OR (world climat* $\left.{ }^{*}\right)$ OR (climat* change $\left.\left.\left.^{*}\right)\right)\right)$ )

\#4 37291 TS = ((photosynthesis OR $\left(\left(\right.\right.$ atmosphe $^{*}$ input $\left.{ }^{*}\right)$ OR (input* SAME atmosphe $\left.\left.{ }^{*}\right)\right)$ OR $(($ primary product* $)$ OR (food web $\left.\left.\left.^{*}\right)\right)\right)$ )

\#5 7874 TS $=((($ DOM OR $($ dissolved organic matter*) $)$ OR (DOC OR (dissolved organic carbon*)) OR (dissolved carbon dioxide $\left.\left.{ }^{*}\right)\right)$

\#6 12952 TS $=\left(\left(\left(\right.\right.\right.$ calcium carbonate biomineralization $\left.{ }^{*}\right)$ OR $\left(\mathrm{CaCO} 3\right.$ biomineralization $\left.{ }^{*}\right)$ OR calcificat $\left.\left.{ }^{*}\right)\right)$

\#7 19587 TS $=\left(\left(\right.\right.$ denitr $^{*}$ OR (nitrogen fixat $\left.{ }^{*}\right)$ OR nitrif* $\left.)\right)$

\#8 2324 TS $=\left(\right.$ sulfate reduct $\left.{ }^{*}\right)$

\#9 17551 TS = ((((inorganic nutrient $\left.{ }^{*}\right)$ OR ((ammonium OR NH4) OR (Si OR silicate OR silice) OR (P OR phosphorus) OR (phosphate OR PO4) OR (Fe OR iron) OR (DIN OR (dissolved inorganic nitrogen)) OR (DIP OR (dissolved inorganic phosphorus)) OR (sul*ur* OR S OR SO4 OR SO3 OR SO2) OR (Zn OR zinc) OR (Mn OR manganese) OR (NO3 OR nitrate*) OR (NO2 OR nitrite*))) SAME flux*))

\#10 133433 TS $=\left(\right.$ respirat $\left.^{*}\right)$

3: Anthropogenic disturbances

\#1 4584 TS $=\left(\right.$ eutrophicat $\left.^{*}\right)$

\#2 1334 TS $=\left(\right.$ greenhouse effect $\left.{ }^{*}\right)$

\#3 64403 TS = (((habitat alteration *) OR ((human OR anthropogenic) SAME (activit* OR perturbat $\left.\left.{ }^{*}\right)\right)$ OR (toxic* AND pollution*) OR (aerosol ${ }^{*}$ same contaminant $^{*}$ ) OR (vir* SAME attack*) OR (disease* AND (((bacterial contamination*) SAME beach*) OR (sewage effluent*) OR (septic tank*) OR (industrial processing) OR farming* OR recreation*)) OR overfishing* OR fishing*))

\#4 $69949 \quad$ \#1 or \#2 or \#3

4: Final step Combination of Searches 1, 2 and 3: 1 AND (2 OR 3) 

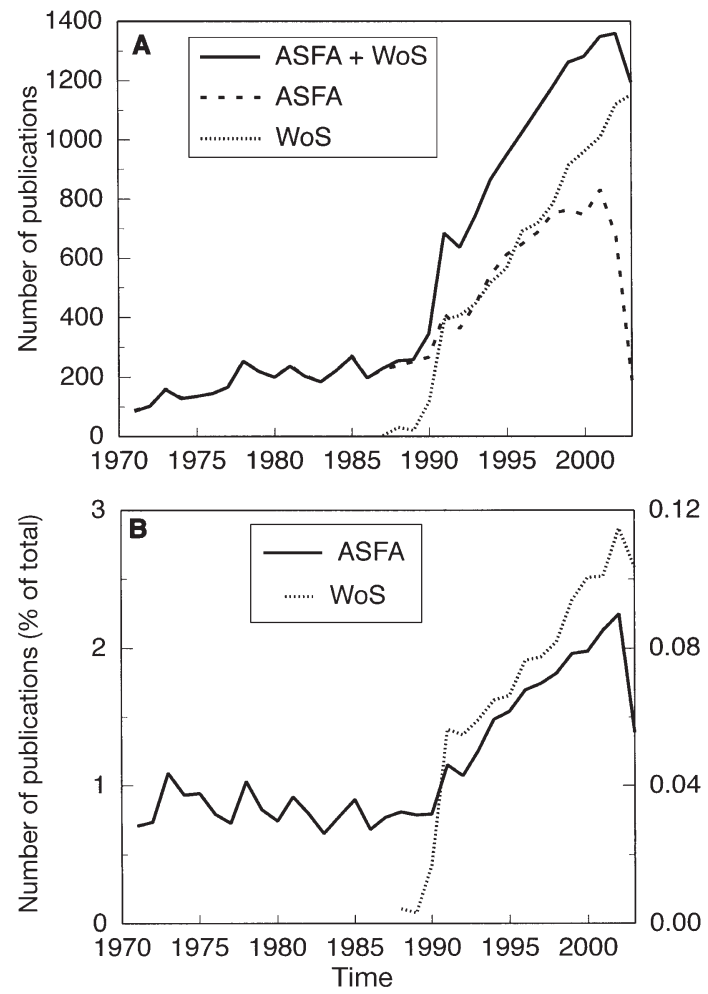

Fig. 1. (A) Number of publications in the field of coastal biogeochemistry recovered from the Aquatic Science and Fisheries Abstracts (ASFA) and Web of Science (WoS) databases, number of publications after merging of the 2 searches and removal of duplicate records (ASFA + WoS). (B) References on coastal biogeochemistry recovered from the ASFA and WoS databases (left and right axes, respectively) expressed in percent of the total number of records archived in those databases

abstract field, the lack of abstracts introduced a bias and a less efficient search. Indeed, the WoS database returned more articles during the period 1997 to 1998, when the number of references without abstract was $<1 \%$. Both databases included a similar number of articles during the period 1991 to 1998. In subsequent years the WoS database clearly returned more references than the ASFA database.

The coverage of sources can explain the different efficiency of the databases to return relevant papers. The mainstream journals are equally well indexed by both products. However, the WoS database has a wider scope and indexed, at the time of analysis, 6106 journals distributed across all scientific disciplines, including journals not primarily concerned with marine science. The ASFA database indexes 4946 journals related to aquatic sciences to a various extent. In some journals $100 \%$ of the articles are indexed (core sources), while in others coverage is $>50 \%$ (priority sources) or $<50 \%$ (selective sources). Additionally, the ASFA database comprises records of reports, articles in conference proceedings, theses and books, although the coverage seems to be limited. Very few of these sources are indexed in the WoS database. It is likely that these evolutions largely result from changes in the sources covered, but it is not possible to confirm because the publishers of these 2 databases do not document such changes.

The decline of records from the ASFA database in 2003 compared to 2002 is most likely due to the fact that the journal issues published late that year were not yet included in the database at the time this study was conducted. Such decline is not found in the WoS database because indexing is much quicker in the WoS than in the ASFA database. The 2 products are clearly complementary. About $23 \%$ of the publications on coastal biogeochemistry published during the period 1988 to 2004 are exclusively imported from the ASFA database, while $48 \%$ come from the WoS exclusively.

Overall, combining the records obtained from the 2 databases, the number of publications on coastal biogeochemistry increased slowly during the period 1971 to 1990 , with an average number of publications of $195 \mathrm{yr}^{-1}$ (Fig. 1A). It subsequently doubled over the period 1992 to 2002. It is well known that the total number of scientific publications has increased considerably over the last 3 decades. For example, the total number of publications indexed by the ASFA database increased 3-fold between 1971 and 2002 (12143 vs. 38 892). However, a clear shift of the publication strategy towards coastal biogeochemistry and disturbances began in 1993. The share of relevant publications was, on average, $0.85 \%$ of the total number of ASFA records during the period 1971 to 1992 (Fig. 1B). It subsequently increased steadily to reach a value of $2.3 \%$ in 2002. The share is much lower in the WoS database, which indexes all disciplines of science and engineering, but a similar increase is found.

\section{Sources}

The database that we compiled (17604 records) comprises 14743 journal articles, 1430 articles in conference proceedings, 930 books or book chapters, 415 reports, 85 theses and 1 computer program. The increase in the number of publications reported in the previous section is mostly due to an increase in the number of journal articles, which rose almost 10 -fold between the periods 1971 to 1981 and 1993 to 2003 (1184 to 10888 ; Fig. 2). Most of the increase occurred after 1992. The number of articles in conference proceedings doubled from 1971-1981 to 1993-2003. The number of books and book chapters increased by $30 \%$ between 1993 and 2003. It is difficult to interpret the changes in the number of sources other than journal articles because their coverage seems very incomplete. 


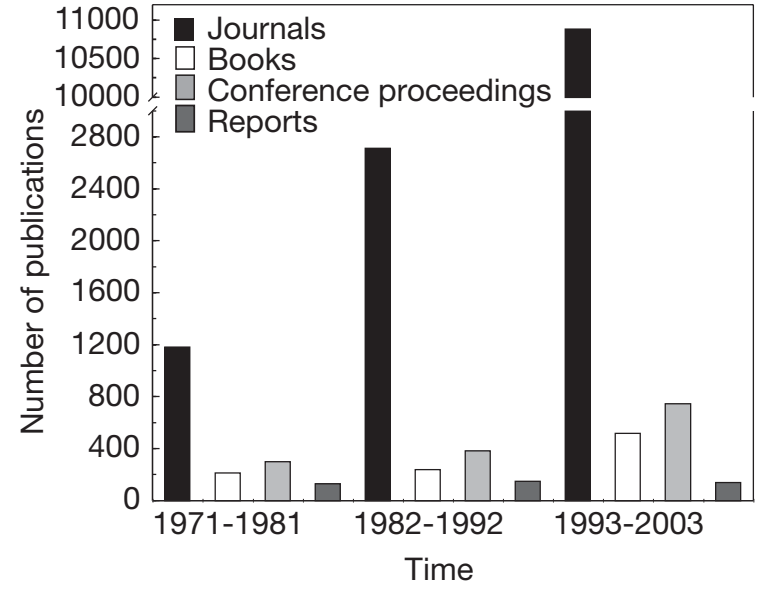

Fig. 2. Number of publications on coastal biogeochemistry published between 1971 and 2003 grouped per type of source document

\section{Ecosystems, biogeochemical processes and elements investigated}

The change in the number of publications devoted to specific types of ecosystems is similar to the one reported above for the whole database, with a steep increase in the early 1990s (Fig. 3). Estuaries and river deltas are by far the most studied ecosystems, with a share of $25 \%$ of the publications relevant to coastal biogeochemistry. This is much higher than their percent surface cover (5.4\% of the coastal zone; Gattuso et al. 1998). Three reasons can explain this increased attention. First, these 2 ecosystems clearly rank among those which are most heavily impacted by human activities. Second, estuaries and river deltas are very diverse and hence require a research effort proportionately higher than other ecosystems to grasp this diversity. Third, they are arguably the most convenient to study, as they have modest requirements in terms of ship size and can be investigated from land-based stations. It is also possible that estuarine papers are overestimated because the North American literature often lumps together coastal lagoons and estuaries. This bias is likely small as references of the ASFA database are indexed using keywords attributed by the publishing staff in addition to the authors' keywords.

Open continental shelves are the second most studied type of coastal ecosystem, but the percent number of publications is disproportionately small compared to their percent surface cover (18\% of the articles vs. $82 \%$ of the coastal surface area; Gattuso et al. 1998), presumably due to its limited access compared with other types of coastal ecosystems. It is surprising that ecosystems exhibiting high rates of primary production, and presumably being important players in the carbon cycle, e.g. algal beds, mangroves, wetlands, salt-marshes and seagrass meadows, have been subject to comparatively few investigations, although their share of the research efforts is approximately scaled to their surface areas (Gattuso et al. 1998). There was no major shift in the proportion of publications devoted to specific ecosystems over the time period investigated.

The cycling of inorganic nutrients is the biogeochemical process receiving the highest research effort $(46 \%$ of the publications; Fig. 4) in keeping with their considerable importance in the coastal zone due to natural and anthropogenic inputs. Almost $1 / 5$ of the papers report on primary production, and almost $15 \%$ report on dissolved organic compounds. The number of publications specifically addressing anthropogenic activities and their effect on coastal biogeochemistry is small $(11 \%)$. This is somewhat surprising since the susceptibility of coastal biogeochemistry to anthropogenic forcings is one of the major features of coastal oceanography. This may be partly due to a bias of the keyword indexing of the WoS database prior to the early 1990s, a
Fig. 3. Number of publications for each type of ecosystem published every year (1971 to 2003): (A) estuaries and river deltas; (B) shelves; (C) coastal sediments and mud flats; (D) lagoons; (E) coral reefs; (F) algal beds; (G) beaches; (H) mangroves forests; (I) coastal wetlands and salt-marshes; (J) others (coastal canyons, submerged banks, polar ecosystems, shallow nearshore habitats, coastal hydrothermal vents, caves and hypersaline coasts); (K) coastal upwellings; and (L) seagrass meadows. The total number of publications published during the period 1971 to 2003 is shown as a percent of the total number of publications on coastal biogeochemistry 


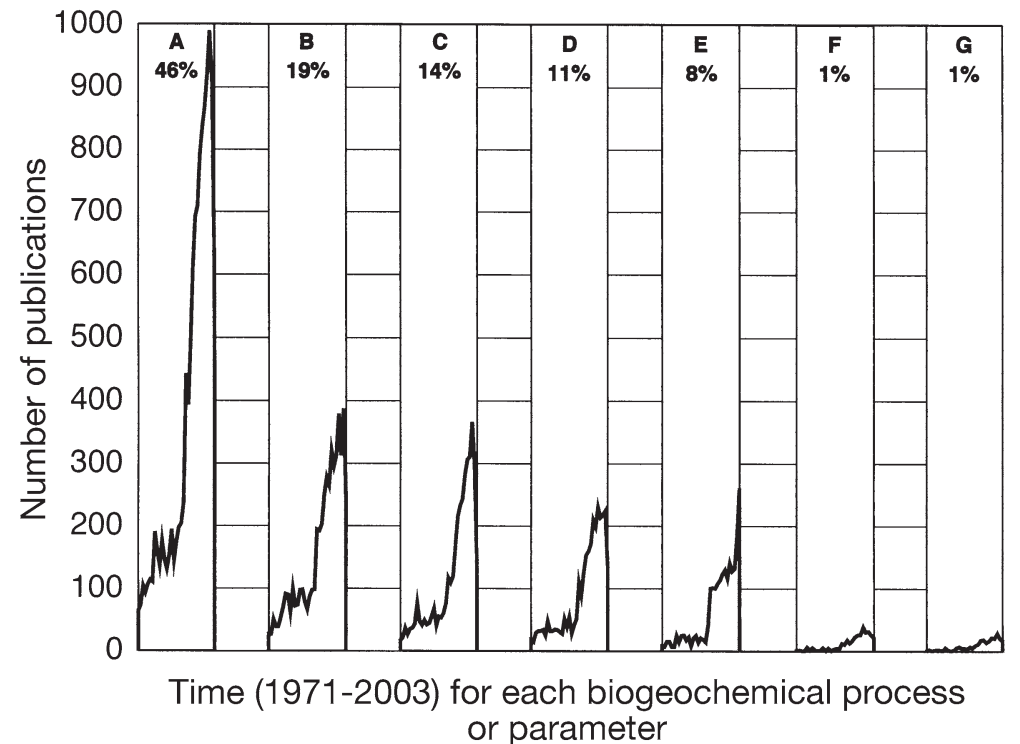

Fig. 4. Number of publications for the main biogeochemical processes and parameters published every year (1971 to 2003): (A) inorganic nutrients; (B) primary production; (C) dissolved organic compounds; (D) anthropogenic activities and disturbances; (E) others (keywords other than A to D, F to G); (F) exchanges with the atmosphere; and (G) fluxes of calcium carbonate. The total number of publications published during the period 1971 to 2003 is shown as a percent of the total number of publications on coastal biogeochemistry

period during which few records included the abstract of the publication. Also surprising is the limited number of studies reporting inputs from and outputs to the atmosphere (only $1.3 \%$ ), as the issue of the role of the coastal ocean as a source or sink of $\mathrm{CO}_{2}$ and other climatically active gases to the atmosphere remains controversial (Smith \& Hollibaugh 1993, Gattuso et al. 1998, Wollast 1998, Rabouille et al. 2001), and the atmosphere is considered to be a major source of nutrients to coastal ecosystems (e.g. Nixon et al. 1996). This may be due to methodological problems that are still unresolved. Similarly, fluxes of calcium carbonate received an amount of attention that seems disproportionately small. Indeed, about $1 / 2$ of the precipitation of calcium carbonate occurs in the coastal ocean (Milliman \& Droxler 1996), and recent evidence showed that it is adversely affected by increasing levels of atmospheric $\mathrm{pCO}_{2}$ (Gattuso et al. 1999, Kleypas et al. 1999). Carbon is the element that is most investigated (30\%), followed by the inorganic forms of nitrogen $(25 \%)$ and phosphorus (12\%) (data not shown).

\section{Size and geographical distribution of the research community}

A total of 28497 authors contributed to publications on the biogeochemistry and perturbations of coastal ecosystems over the period 1971 to 2003. This number, which provides an (under) estimation of the human contingency involved in coastal biogeochemistry, is probably underestimated due to the indexing limitations mentioned in the 'Methods' section. The total number of distinct authors in the field of coastal biogeochemistry and disturbances increased slightly between 1971 and 1987, with an average annual number of 328 contributing authors over that period (Fig. 5). This number increased sharply between 1987 and 2002 (411 vs. 4263). There was a $>30$-fold increase over the period of investigation (1971 to 2002), consistent with the increase of the number of publications reported earlier. The average number of authors per publication increased from about 2 in 1982 to 3.2 in 2002. The largest number of authors for a single article is 29 (MacDonald et al. 2000). Coastal biogeochemistry is an interdisciplinary research field, and the growing importance of large funding agencies (e.g. the National Science Foundation and the Framework Programs of the European Union), which promote larger field campaigns as well as national and international collaborations, likely prompted the formation of larger research groups.

The distribution of authors reporting on specific types of ecosystems is similar to the distribution reported above for the number of publications, with a steep increase in the early 1990s (Fig. 6). The percent of authors working on estuaries and river deltas did not change significantly over time, remaining at about $26 \%$ every year. In contrast, there are some changes in

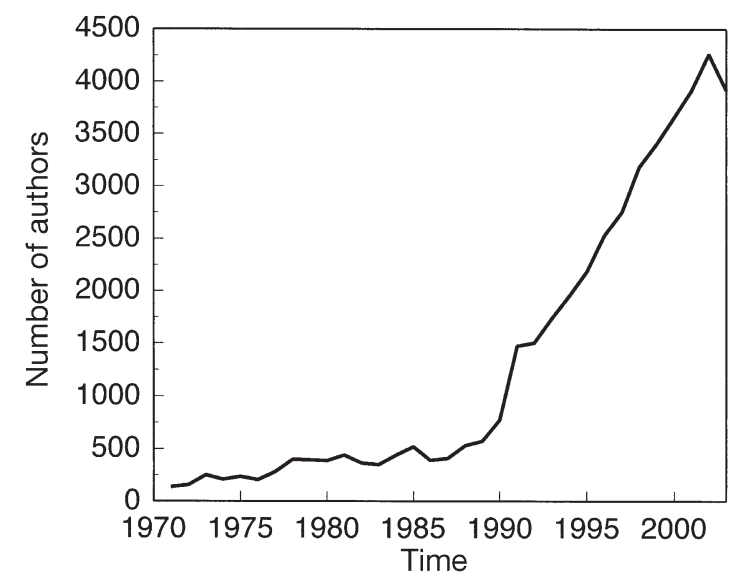

Fig. 5. Number of authors involved in publications on coastal biogeochemistry every year 


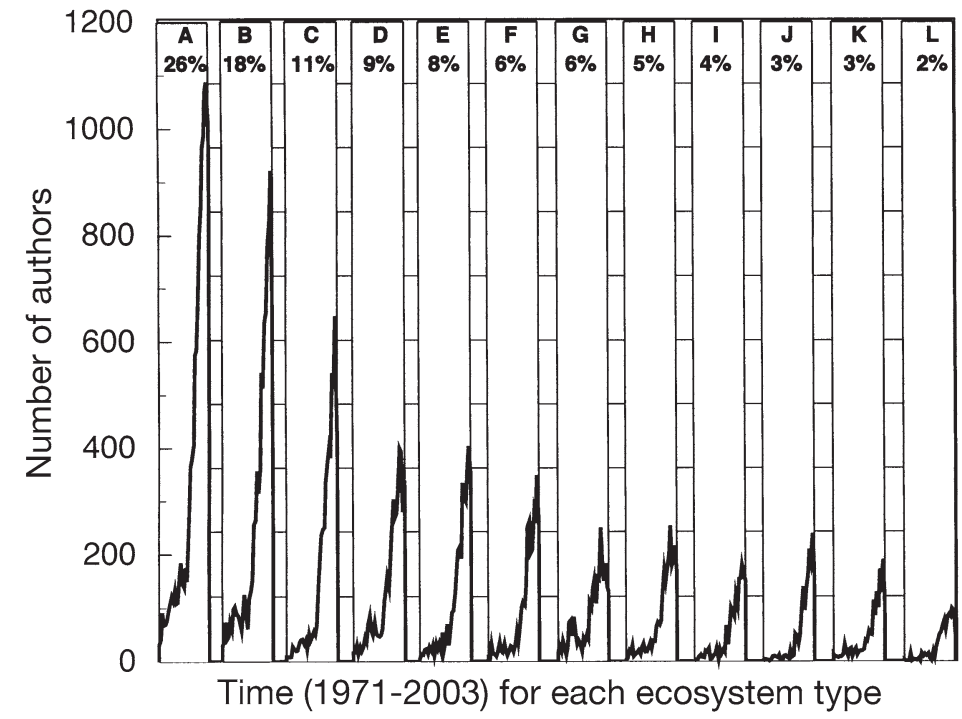

Fig. 6. Number of authors involved in publications devoted to specific ecosystems. Each author was counted once per year. The total number of authors for each type of ecosystem is shown as a percent of the total number of publications on coastal biogeochemistry published during the period 1971 to 2003. See the legend of Fig. 3 for ecosystem coding
The European Union (EU25) is well represented with about $1 / 3$ of all senior authors. The EU contingent was led, numerically, by scientists from France, the United Kingdom, Germany, Italy, Spain, the Netherlands, Denmark, Sweden, Portugal, Belgium, Greece, Poland and Finland. As indicated above, there is a long tradition of coastal research in Europe, where the first marine stations were established. Moreover, France and the United Kingdom still sustain colonies or overseas territories.

To compare the contributions of different countries, it is instructive to compare the number of publications per country relative to population and to gross domestic product (GDP). The publication intensity (publication per million inhabitants) is highly correlated to wealth intensity (GDP per person; $\mathrm{r}^{2}=0.84$;

\section{Number of publications} (\% of total)

the distribution of research contingents to other ecosystems. For instance, the number of authors working on coastal sediments and mud flats doubled (6 to 12\%) between 1971 and 2003, whereas those working on beaches decreased from 12 to $4 \%$ during the same time interval. The relationship between the percent of authors and the percent of publications in each system is highly significant $\left(\mathrm{r}^{2}=0.99\right)$, with a slope of 0.98 , and none of the ecosystems is greatly offset from the 1:1 line (data not shown). Indeed, the increase in the size of research teams, as indicated by the average number of authors per paper, is paralleled by an increase in the total publication output.

Senior authors are affiliated to institutions within 137 countries. Those from US institutions comprise the largest contingent, with a little less than $30 \%$ of all of the senior authors (Fig. 7). Interestingly, the US have a significantly larger share $(50 \%)$ when the whole field of ocean science and technology is considered (Dastidar 2004). The institutions contributing most researchers were located in California, Florida, Massachusetts, New York and North Carolina. Florida and California have the longest coastlines of all US states, except Alaska (respectively, 1350 and $2170 \mathrm{~km}$ at a scale of 1:1200 000). Moreover, California and Florida are 2 states where laboratories affiliated to universities are numerous and competitive. Other states prominent in marine research are located on the east coast (Massachusetts, Maryland, Virginia, Georgia, Rhode Island, New Jersey, the District of Columbia and Maine).

$\begin{array}{lllllll}0 & 2 & 4 & 6 & 8 & 30 & 36\end{array}$

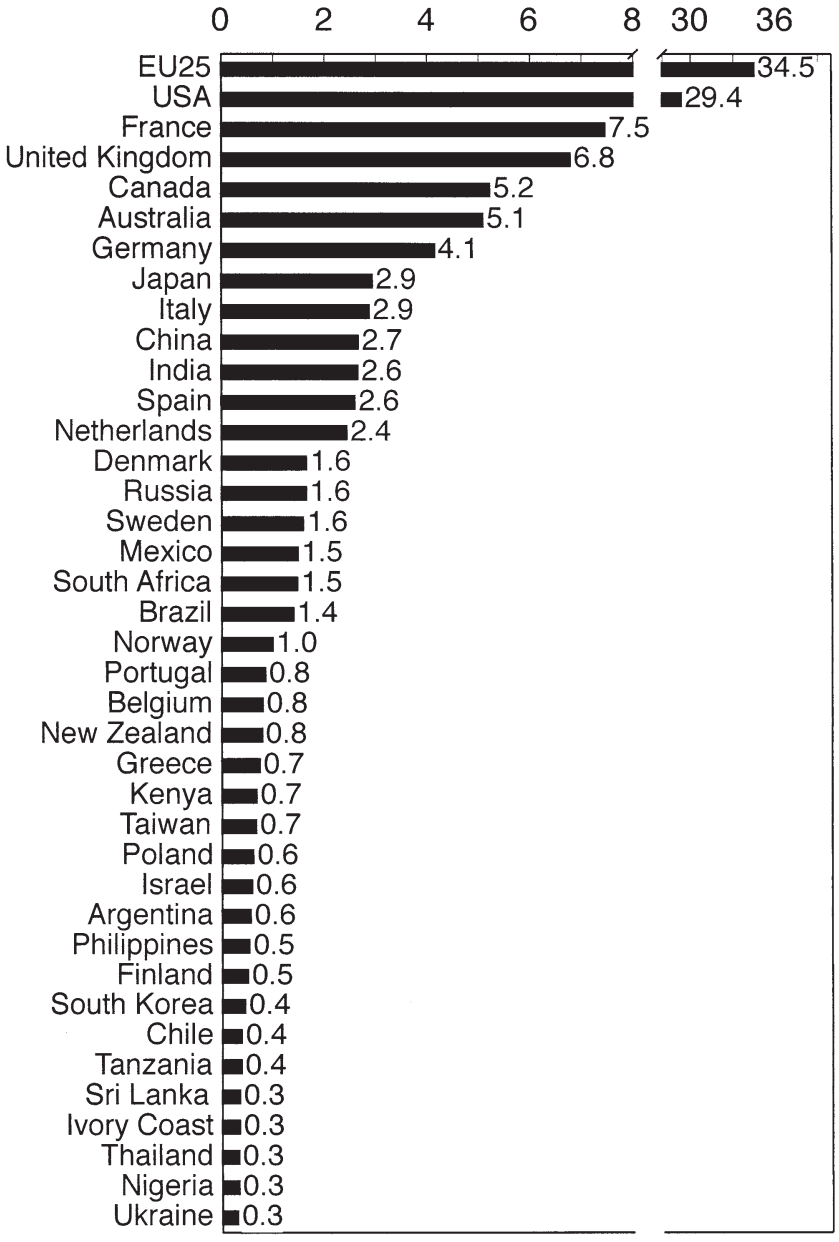

Fig. 7. Geographical distribution of senior authors. Only countries with $>50$ references on coastal biogeochemistry published during the period 1971 to 2003 are shown 


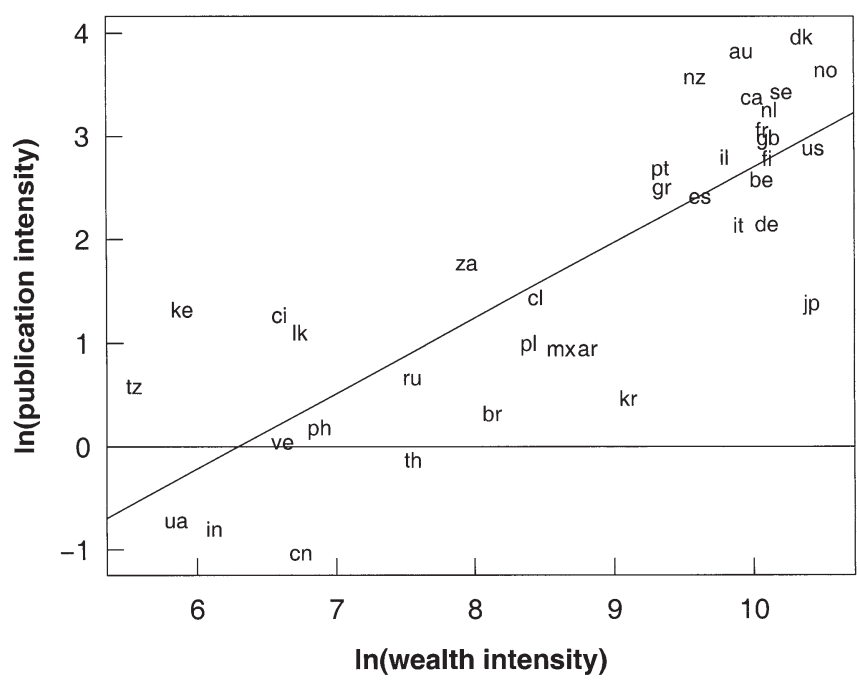

Fig. 8. Publication intensity (publication per million inhabitants) for the years 1971 to 2003 as a function of wealth intensity (gross domestic product in US-\$ per inhabitant) for the years 1988 to 2002. The regression line is shown. Publications were distributed among the countries using the affiliation of the first author as a criterion. Only countries with $>50$ references published during the period 1971 to 2003 are shown. Key to countries, according to ISO 3166, are printed in lower case to minimize overlap (ar, Argentina; au, Australia; be, Belgium; br, Brazil; ca, Canada; ci, Ivory Coast; cl, Chile; cn, China; de, Germany; dk, Denmark; es, Spain; fi, Finland; fr, France; gb, United Kingdom; gr, Greece; il, Israel; in, India; it, Italy; jp, Japan; ke, Kenya; kr, South Korea; lk, Sri Lanka; mx, Mexico; nl, Netherlands; no, Norway; nz, New Zealand; ph, Philippines; pl, Poland; pt, Portugal; ru, Russian Federation; se, Sweden; th, Thailand; tz, United Republic of Tanzania; ua, Ukraine; us, United States; ve, Venezuela; za, South Africa). Note that Taiwan is not shown because its gross domestic product is not listed in the World Bank database

$\mathrm{p}=2 \times 10^{-15} ;$ Fig. 8). The Scandinavian countries clearly perform strongly in coastal biogeochemistry, consistent with their performance in science in general (King 2004). Australia, New Zealand and Canada, countries with an extended coastline and strong oceanographic universities and research institutions, have a high publication intensity in coastal biogeochemistry and disturbances. Japan, Germany and Italy appear to underperform in coastal biogeochemistry based on these measures.

\section{Study sites}

The coastal zones of the NE and NW Atlantic Ocean (respectively, 19.4 and $12 \%$ of the study sites) and the Mediterranean (9.6\%) rank among the most investigated geographical areas, together comprising $41 \%$ of the study sites (Fig. 9A). The SW Atlantic Ocean, western Pacific and Indian Ocean are also well investi- gated, each representing about $10 \%$ of the study sites. The other areas comprise 1 to $6 \%$ of the study sites.

The geographical distribution of study sites is poorly scaled to the surface area of the coastal zones (Fig. 9B). The research effort in some zones (e.g. the North Atlantic and the Mediterranean Sea) is disproportionately higher than their surface areas. In contrast, the research efforts in the high latitudes and the western Pacific are disproportionately low compared to their surface area. In fact, the geographical distribution of effort is likely partly driven by the distribution of scientists. The fact that the North Atlantic Ocean and the Mediterranean Sea represent $41 \%$ of the study sites is in good agreement with the observation reported in the previous section that the east coast of the USA and Europe host the largest contingencies of senior authors. It must of course be recognized that there is no necessary link between the affiliation and location of study site, as it is quite common for authors to conduct their research at distant field locations. Although we have no data on the distribution of funding, it is also quite obvious that the areas most investigated are those bordered by countries strongly supporting and with a long tradition of coastal research (e.g. the USA and EU). In contrast, other areas, such as the West African coast, have rarely been studied, with $<4 \%$ of the study sites. There are exceptions, for example, coastal research is not known to be particularly well supported in most countries bordering the Indian Ocean, yet $>10 \%$ of the study sites are located in this area.

\section{Citations}

It may be surprising that about $20 \%$ of the articles have never been cited (Fig. 10). A similar figure was obtained with books and book chapters (data not shown). In fact, this is a general situation. For example, $22.4 \%$ of the scientific articles published in 1984 remained uncited at the end of 1988 (Pendelbury 1991). Moreover, this figure must be interpreted with caution because it generally takes $>1$ yr for a newly published paper to be cited. Our database comprises 1193 articles published in 2003, thus explaining about $1 / 3$ of the $20 \%$ of uncited journal articles. About $63 \%$ of the articles received between 1 and 20 citations, and $16 \%$ have been cited $>21$ times. These data suggest that, although a relatively large number of scientists (17415 over 1971 to 2003 in the WoS database) published in the field of coastal biogeochemistry, they are distributed in a relatively closed group, probably centered on specific types of ecosystems or biogeochemical processes. The number of citations in each group would be small due to the small size of the community.

The 20 most cited articles and the 5 most cited 


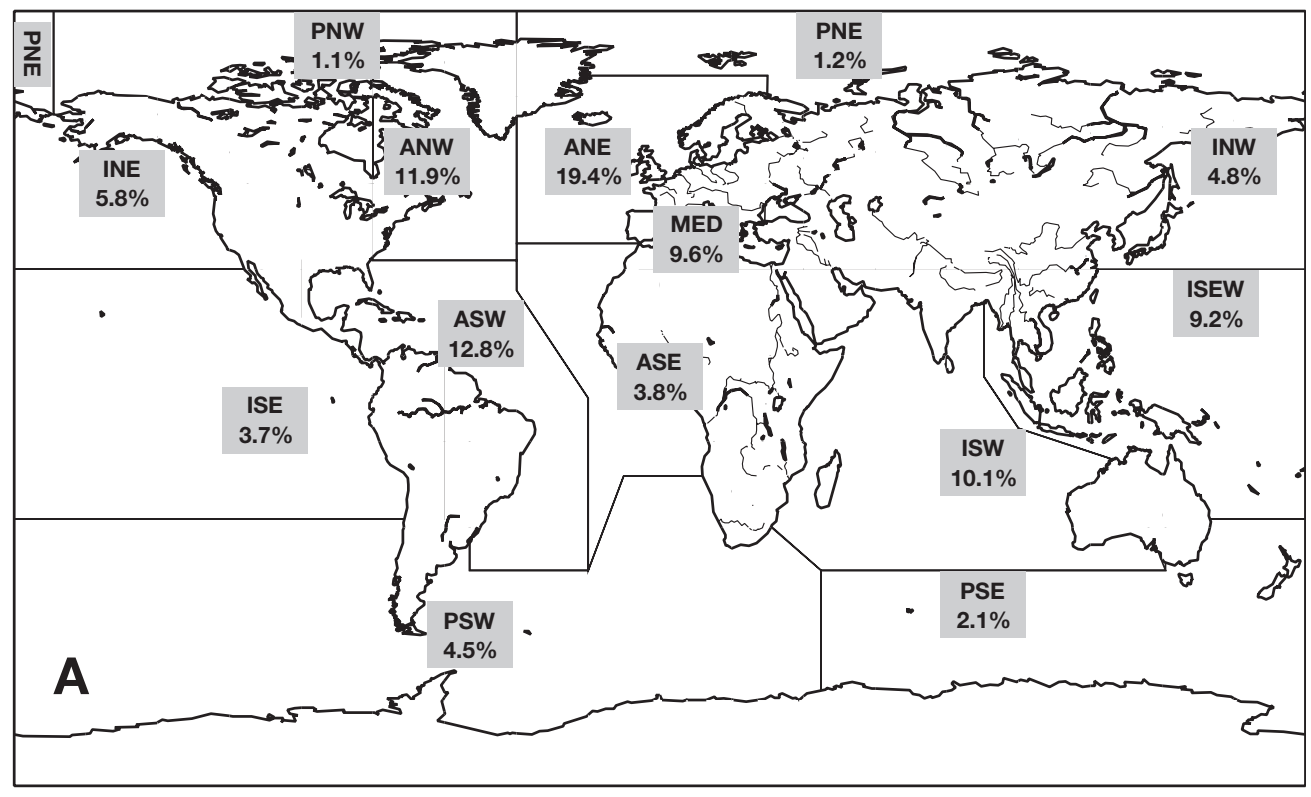

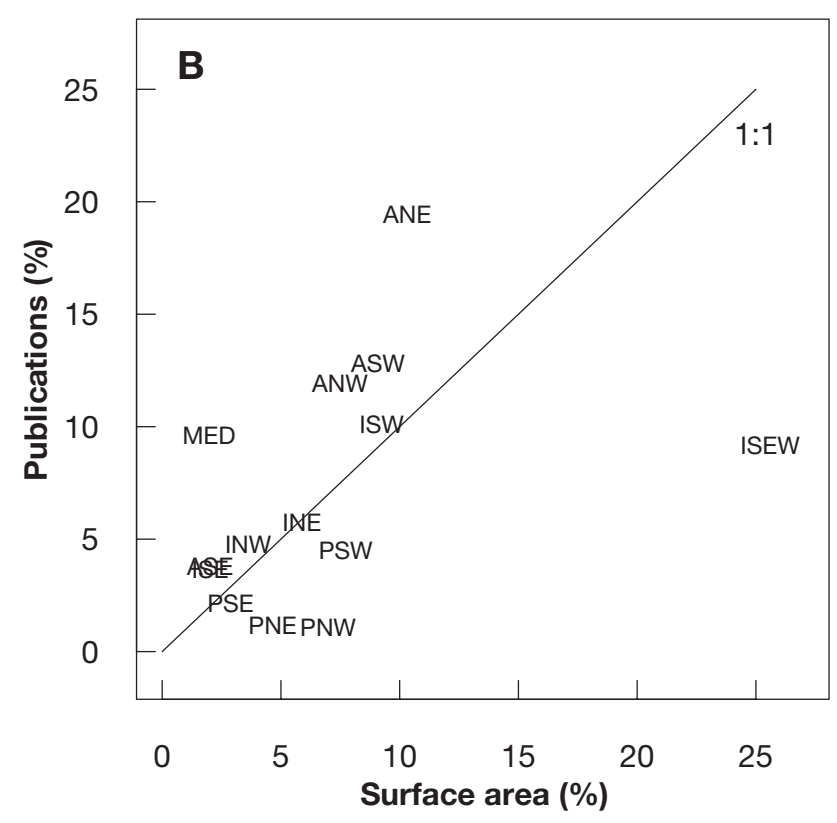

monographs are listed respectively in Tables $2 \& 3$. The 3 most cited articles are general papers which include one of the coastal keywords that we used, but are not specifically related to coastal research. Interestingly, only 3 of the most cited papers were published in journals with the highest impact factors (Institute for Scientific Information 1998), such as Science and Nature (Table 2). This suggests that either these journals do not attract highly significant and original research on coastal biogeochemistry or that publishing in these journals does not guarantee a high number of citations. This must be balanced because these 2 journals only published 151 papers
Fig. 9. (A) Geographical distribution of the study sites of publications published during the period 1953 to 2003. Locations were extracted from the Aquatic Science and Fisheries Abstracts (ASFA) database. Note that some papers investigated sites located in 2 regions or more. Data are expressed as a percent of the total number of geographical keywords found in the ASFA database. This analysis was carried out on references obtained from the ASFA database. (B) Number of publications (percent of the number of records recovered from the ASFA database) with study sites located in specific geographical zones as a function of the surface area of the coastal ocean of each zone (percent of the surface area of the global coastal ocean). This analysis was carried out with references obtained from the ASFA database. The 2 labels which overlap are ASE and ISE. The 1:1 line is shown (ANE, northeastern Atlantic; ANW, northwestern Atlantic; ASE, southeastern Atlantic; ASW, southwestern Atlantic; INE, northeastern Indian; INW, northwestern Indian; ISE, southeastern Indian; ISW, southwestern Indian; ISEW, southwestern Pacific; MED, Mediterranean; PNE, northeastern Pacific; PNW, northwestern Pacific; PSE/PSW, polar Antarctic) on coastal biogeochemistry and disturbances $1 \%$ of the total) over the past $32 \mathrm{yr}$. The average number of references cited in the reference sections of papers on coastal biogeochemistry is 57, and is larger for highly cited papers. These have long reference lists (articles cited >201 times list, on average, 138 references) as most are review articles.

\section{Journal articles}

Journal articles represent about $84 \%$ of the 17604 records extracted from the ASFA and WoS databases. 


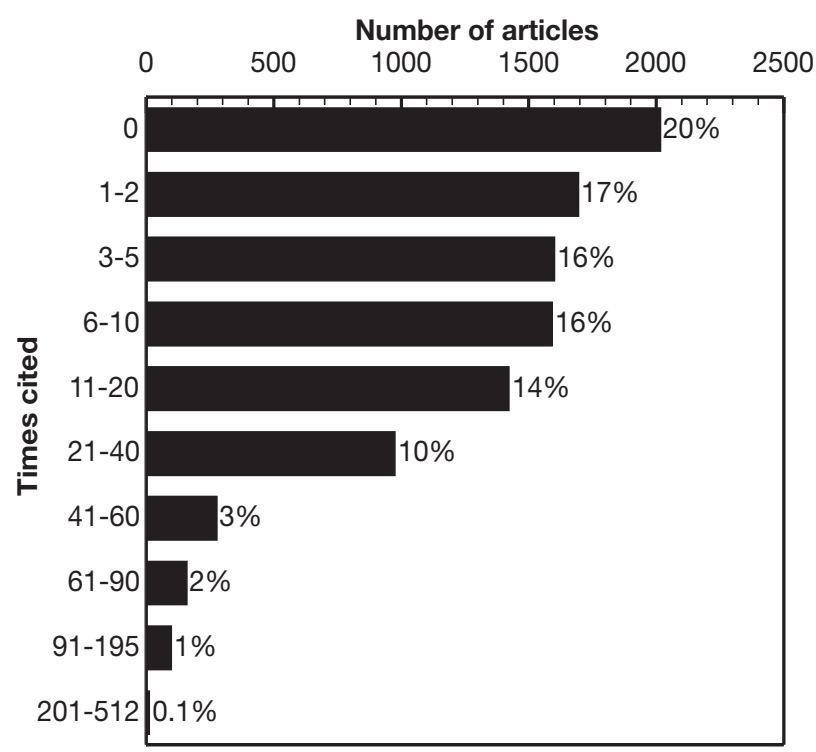

Fig. 10. Frequency distribution of the number of citations of articles. This analysis was carried out on references obtained from the World of Science database

Eight of these papers were omitted from the analysis because they lacked either the journal name or the publication year. The rate of publication increased from 137 papers per year in the period 1971 to 1990 to 1250 papers per year in 2002. Journal articles published between 1953 and 2003 were scattered in 1804 periodicals or periodical series. The distribution is highly biased with 1554 journals each publishing <10 relevant papers during the period investigated (Fig. 11), while 23 journals each published $>100$ relevant papers (Fig. 12). This demonstrates both the highly disciplinary nature of coastal biogeochemistry and disturbance, as well as the existence of a large number of journals with a local, regional or ecosystemspecific scope.

Among the 23 most relevant journals, only 4 have a multidisciplinary scope extending beyond aquatic sciences (Journal of Geophysical Research, Geochimica et Cosmochimica Acta, Science of the Total Environment and Palaeogeography Palaeoclimatology Palaeoecology). Although only $9 \%$ of the pages published in Marine Ecology Progress Series (MEPS) are relevant, this journal publishes the largest number of relevant papers (Fig. 12), being therefore the single most important source of literature on coastal biogeochemistry and disturbance. More specialized journals, such as Estuaries and Estuarine, Coastal and Shelf Science (ECSS) dedicate, respectively, 19 and $53 \%$ of their pages to relevant articles, but the absolute number of articles is lower. The reason is that Estuaries and ECSS publish fewer pages than MEPS every year (on aver-

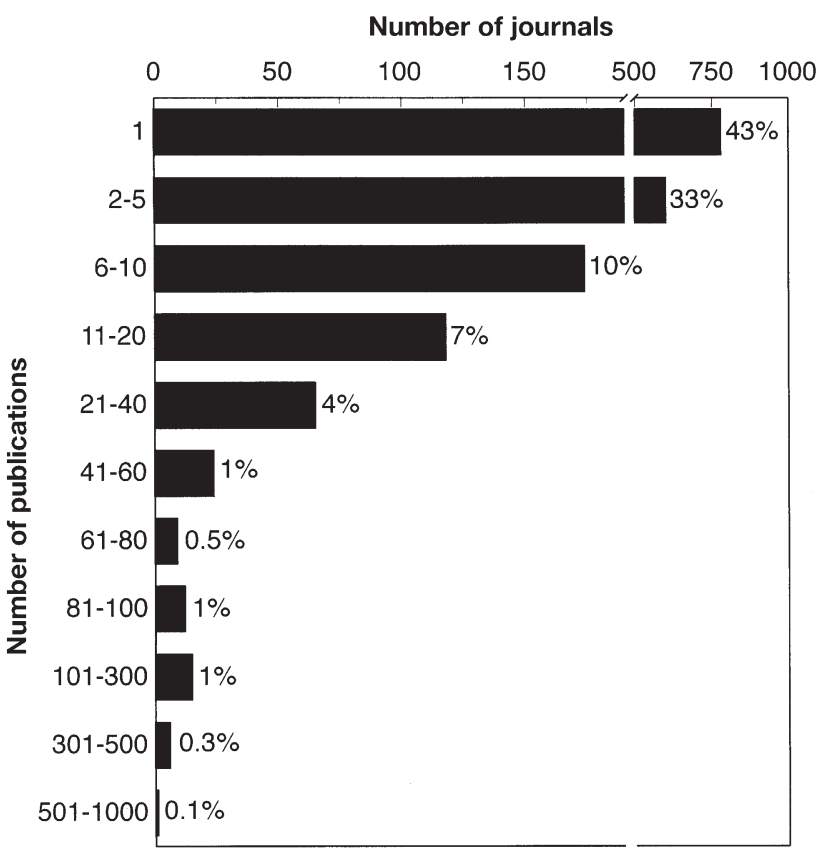

Fig. 11. Frequency distribution of the number of journal articles

age 644 and 822 vs. 3286).

\section{Conclusions}

This bibliometric study provides a clear picture of how the status of research on coastal biogeochemistry and disturbances has evolved during the past $23 \mathrm{yr}$. It also identifies imbalances in the distribution of study sites and allocation of efforts in certain ecosystems and disciplinary areas. Finally, it identifies the challenges which lie ahead.

Research on coastal biogeochemistry and disturbances has increased rapidly over the period investigated. This increase was higher than that of the general increase observed for scientific research, as shown by the doubling of the number of publications devoted to that field scaled to the total number of scientific publications. The total number of authors is very large and obviously underestimates the total number of scientists working in the field, as technicians and students are not always co-authors. The reasons for the major increase in coastal biogeochemistry research in the 1990s are probably manifold. First, recognition of the disproportionate role of the coastal zone on biogeochemical processes and the major human impacts on coastal ecosystems is relatively recent, with research on coastal eutrophication lagging 2 decades behind that on freshwater ecosystems (Vidal et al. 1999). Furthermore, an awareness of the large-scale habitat destruction of coastal habitats is also relatively recent (e.g. Valiela et al. 2001, Duarte 2002). Second, the launch of relatively large-scale international, regional 
Table 2. List of the 20 most cited papers. This analysis was carried out on references obtained from the database

\begin{tabular}{|c|c|}
\hline $\begin{array}{l}\text { Times } \\
\text { cited }\end{array}$ & Reference \\
\hline 512 & Trenberth KE, Hurrell JW (1994) Decadal atmosphere-ocean variations in the Pacific. Clim Dyn 9:303-319 \\
\hline 412 & Lovley DR (1991) Dissimilatory Fe (III) and Mn (IV) reduction. Microbiol Rev 55:259-287 \\
\hline 397 & $\begin{array}{l}\text { Vitousek PM, Aber JD, Howarth RW, Likens GE, Matson PA, Schindler DW, Schlesinger WH, Tilman DG (1997) } \\
\text { Human alteration of the global nitrogen cycle: sources and consequences. Ecol Appl 7:737-750 }\end{array}$ \\
\hline 356 & $\begin{array}{l}\text { Milliman JD, Syvitski JPM (1992) Geomorphic/tectonic control of sediment discharge to the ocean: the importance } \\
\text { of small mountainous rivers. J Geol 100:525-544 }\end{array}$ \\
\hline 354 & $\begin{array}{l}\text { Hughes TP (1994) Catastrophes, phase shifts, and large-scale degradation of a Caribbean coral reef. Science } \\
\text { 265:1547-1551 }\end{array}$ \\
\hline 314 & $\begin{array}{l}\text { Bryan GW, Langston WJ (1992) Bioavailability, accumulation and effects of heavy-metals in sediments with special } \\
\text { reference to United Kingdom estuaries - a review. Environ Pollut 76:89-131 }\end{array}$ \\
\hline 238 & Ducklow HW, Carlson CA (1992) Oceanic bacterial production. Adv Microb Ecol 12:113-181 \\
\hline 235 & $\begin{array}{l}\text { Carlson PR, Yarbro LA, Barber TR (1994) Relationship of sediment sulfide to mortality of Thalassia testudinum in } \\
\text { Florida Bay. Bull Mar Sci 54:733-746 }\end{array}$ \\
\hline 229 & $\begin{array}{l}\text { Hedges JI, Keil RG (1995) Sedimentary organic matter preservation: an assessment and speculative synthesis. Mar } \\
\text { Chem 49:81-115 }\end{array}$ \\
\hline 211 & $\begin{array}{l}\text { Carpenter SR, Caraco NF, Correll DL, Howarth RW, Sharpley AN, Smith VH (1998) Nonpoint pollution of surface } \\
\text { waters with phosphorus and nitrogen. Ecol Appl 8:559-568 }\end{array}$ \\
\hline 201 & $\begin{array}{l}\text { Mann ME, Bradley RS, Hughes MK (1999) Northern hemisphere temperatures during the past millennium: } \\
\text { inferences, uncertainties, and limitations. Geophys Res Lett 26:759-762 }\end{array}$ \\
\hline 195 & Glynn PW (1993) Coral reef bleaching: ecological perspectives. Coral Reefs 12:1-17 \\
\hline 193 & $\begin{array}{l}\text { Menge BA (1995) Indirect effects in marine rocky intertidal interaction webs: patterns and importance. Ecol Monogr } \\
\text { 65:21-74 }\end{array}$ \\
\hline 192 & $\begin{array}{l}\text { Hutchins DA, Bruland KW (1998) Iron-limited diatom growth and Si:N uptake ratios in a coastal upwelling regime. } \\
\text { Nature 393:561-564 }\end{array}$ \\
\hline 182 & $\begin{array}{l}\text { O'Reilly JE, Maritorena S, Mitchell BG, Siegel DA, Carder KL, Garver SA, Kahru M, McClain C (1998) Ocean color } \\
\text { chlorophyll algorithms for SeaWiFS. J Geophys Res Oceans 103:24937-24953 }\end{array}$ \\
\hline 177 & $\begin{array}{l}\text { Walsh JJ (1991) Importance of continental margins in the marine biogeochemical cycling of carbon and nitrogen. } \\
\text { Nature 350:53-55 }\end{array}$ \\
\hline 177 & $\begin{array}{l}\text { Canfield DE, Thamdrup B, Hansen JW (1993) The anaerobic degradation of organic matter in Danish coastal } \\
\text { sediments: iron reduction, manganese reduction, and sulfate reduction. Geochim Cosmochim Acta 57:3867-3883 }\end{array}$ \\
\hline 171 & $\begin{array}{l}\text { Hoegh-Guldberg O (1999) Climate change, coral bleaching, and the future of the world's coral reefs. Mar Freshw } \\
\text { Res 50:839-866 }\end{array}$ \\
\hline 169 & $\begin{array}{l}\text { Dayton PK, Thrush SF, Agardy MT, Hofman RJ (1995) Environmental effects of marine fishing. Aquat Conserv } \\
\text { Mar Freshw Ecosyst 5:205-232 }\end{array}$ \\
\hline 168 & $\begin{array}{l}\text { Warwick RM (1993) Environmental-impact studies on marine communities — pragmatical considerations. Aust } \\
\text { J Ecol 18:63-80 }\end{array}$ \\
\hline
\end{tabular}

Table 3. List of the 5 most cited monographies. This analysis was carried out on references obtained from the WoS database

\begin{tabular}{ll}
$\begin{array}{l}\text { Times } \\
\text { cited }\end{array}$ & \multicolumn{1}{c}{ Reference } \\
\hline 233 & $\begin{array}{l}\text { Diaz RJ, Rosenberg R (1995) Marine benthic hypoxia: a review of its ecological effects and the behavioural } \\
\text { responses of benthic macrofauna. Oceanogr Mar Biol Annu Rev 33:245-303 }\end{array}$ \\
165 & $\begin{array}{l}\text { Jennings S, Kaiser MJ (1998) The effects of fishing on marine ecosystems. Adv Mar Biol 34:201-352 } \\
112\end{array}$ \\
103 & $\begin{array}{l}\text { Arntz WE, Brey T, Gallardo VA (1994) Antarctic zoobenthos. Oceanogr Mar Biol Annu Rev 32:241-304 } \\
\text { (1995) Production and consumption of biological particles in temperate tidal estuaries. Oceanogr Mar Biol Annu Rev } \\
\text { 33:1-149 } \\
\text { Britton JC, Morton B (1994) Marine carrion and scavengers. Oceanogr Mar Biol Annu Rev 32:369-434 }\end{array}$ \\
&
\end{tabular}


and national research programs in the late 1980s and early 1990s provided the momentum required to consolidate a research community on coastal biogeochemistry and disturbances and increased the opportunities for collaborative research, as indicated by the increase in the average number of co-authors on publications. Third, the growth of scientific societies that group scientists addressing biogeochemical processes in the coastal ocean, either specialized (e.g. American Society of Limnology and Oceanography, Estuarine Research Federation and International Society for Reef Studies) or wider in scope (e.g. European Geosciences Union and American Geophysical Union), has provided an appropriate forum to disseminate results and interact. Not surprisingly, the research community estimated from the country of affiliation of senior authors is highly dominated by the USA and the European Union, the areas where thematic programs and scientific societies have managed to mobilize the research community.

However, the relatively low number of citations per paper suggests that the research community is still structured around themes that do not fully interact with each other. One of the reasons may be that the publications are scattered in a large number of journals. The top 23 journals captured about $40 \%$ of the journal articles, and $86 \%$ of the journals published $<10$ papers during the period investigated. Indeed, the success of review papers suggests that there is a growing demand, likely prompted by the rapid growth and fragmentation of the literature, to provide updated topical syntheses of developments in coastal biogeochemistry and disturbances.

The fragmentation of the literature probably reflects the fragmented nature of the research community, with a consequent paucity of coordination of efforts that results in major imbalances in the development of coastal biogeochemistry. This imbalance is evident throughout the results presented above. The allocation of efforts among coastal ecosystems is highly imbalanced compared to their relative surface area. Two contrasting examples are estuaries and river deltas, which are over-investigated, and open continental
Number of papers

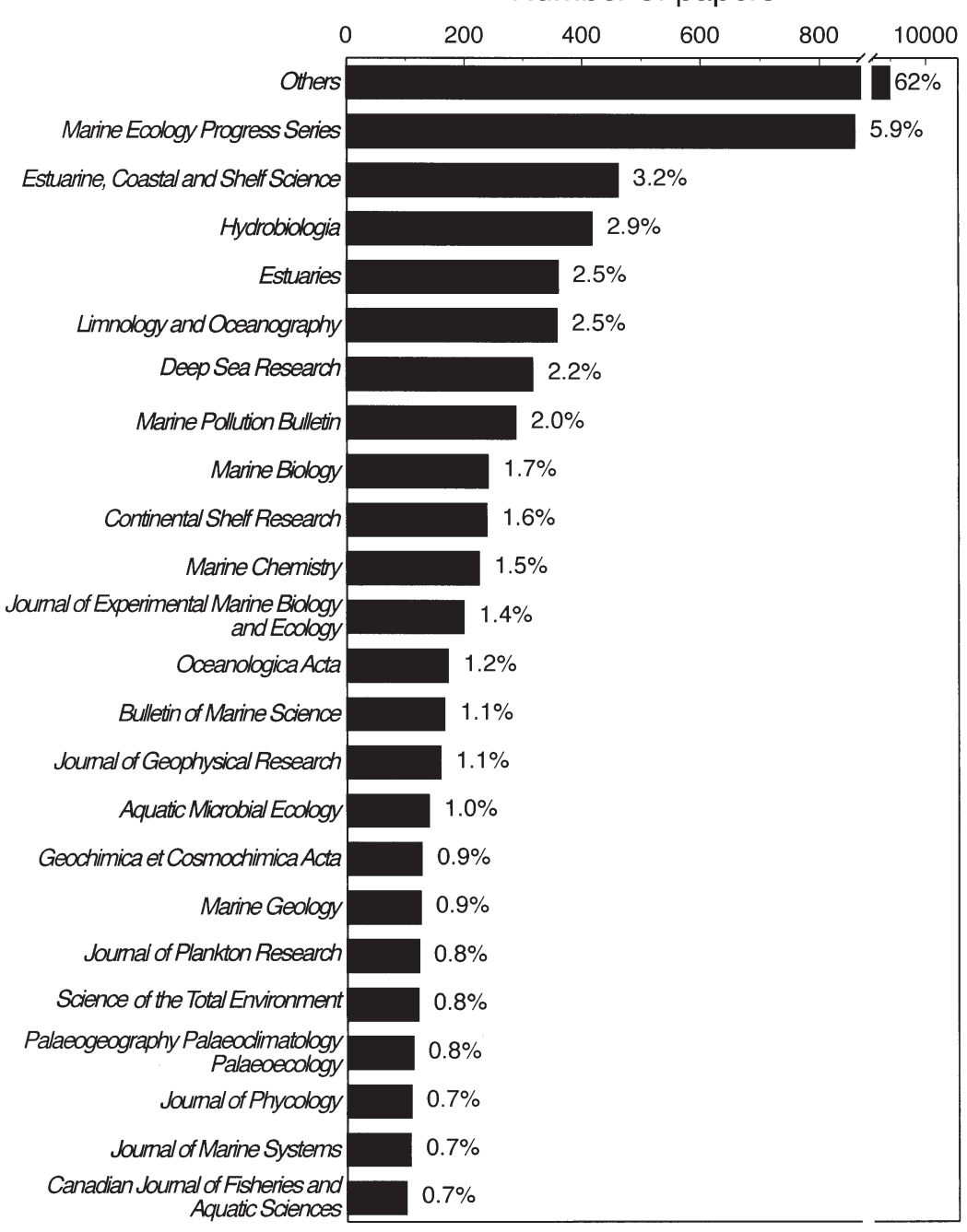

Fig. 12. Number of papers published by the 23 journals which published $>100$ papers on coastal biogeochemistry and disturbances during the period 1953 to 2003. The number of papers on the same topic published during the same period in other journals is also shown ('Others')

shelves, which are grossly under-investigated. Previous papers have already outlined this imbalance, which represents a major obstacle when scaling up elemental fluxes to the global coastal ocean (e.g. Gattuso et al. 1998, Gazeau et al. 2004). Some critical biogeochemical processes, such as gas exchange across the air-sea interface, are also under-investigated. Finally, major imbalances in the distribution of study sites were also found. The research effort in the North Atlantic Ocean and the Mediterranean Sea is disproportionately large compared to their surface area. The high latitude areas, which will be most affected by global climatic change, and other areas, such as the western Pacific, are largely underinvestigated.

Regional, national and international authorities have 
been highly successful in promoting research on coastal biogeochemistry and disturbances, as shown by indicators of the size and output of the research community. The diagnostic derived from this analysis shows that these efforts need to be better coordinated in order to address the imbalances that presently limit the use of the results derived from the growing expenditures on coastal biogeochemistry research. Only improved coordination, both within the research community and the funding agencies, will steer attention to geographical areas and processes which remain poorly investigated, through reallocation of funding within the research programs that they manage. This is crucial to address the present imbalances that impair research progress on coastal biogeochemistry and disturbances. Only then can the role of the coastal ocean on global biogeochemical cycles and its response to climatic and anthropogenic disturbances be clarified.

Acknowledgements. This research was supported by the European Union (EU) in the framework of the EUROTROPH project (contract no. EVK3-CT-2000-00040), and through CNRS-CSIC and France-The Netherlands cooperative agreements. It is a contribution to the Networks of Excellence MARBEF and EUR-OCEAN, and to the Integrated Project CarboOceans of the EU. We gratefully acknowledge the invaluable assistance of E. Baltzinger, librarian of the Monaco Oceanographic Museum, M. Fioroni, librarian of the Observatoire Océanologique de Villefranche, S. Maria, librarian of the Observatoire Océanologique de Banyuls, B. Gentili as well as the editors of several journals. Comments from J. Carpine-Lancre as well as 3 anonymous referees significantly improved an earlier version of this paper. C.M.D. was supported by a sabbatical grant from the Spanish Ministry of Education and Science.

\section{LITERATURE CITED}

Costanza R, d'Arge R, de Groot R, Farber S and 9 others (1997) The value of the world's ecosystem services and natural capital. Nature 387:253-259

Darwin C (1842) The structure and distribution of coral reefs. Smith Elder, London

Dastidar PG (2004) Ocean science and technology research across the countries: a global scenario. Scientometrics 59: $15-27$

Derry LA, Murray RW (2004) Continental margins and the sulfur cycle. Science 303:1981-1982

Dickson JH, Richards MP, Hebda RJ, Mudie PJ and 9 others

Editorial responsibility: Otto Kinne (Editor-in-Chief), Oldendorf/Luhe, Germany
(2004) Kwaday Dan Ts'inchi, the first ancient body of a man from a North American glacier: reconstructing his last days by intestinal and biomolecular analyses. Holocene 14:481-486

Duarte CM (2002) The future of seagrass meadows. Environ Conserv 29:192-206

Gattuso JP, Frankignoulle M, Wollast R (1998) Carbon and carbonate metabolism in coastal aquatic ecosystems. Annu Rev Ecol Syst 29:405-434

Gattuso JP, Allemand D, Frankignoulle M (1999) Photosynthesis and calcification at cellular, organismal and community levels in coral reefs: a review on interactions and control by carbonate chemistry. Am Zool 39:160-183

Gazeau F, Smith SV, Gentili B, Frankignoulle M, Gattuso JP (2004) The European coastal zone: characterization and first assessment of ecosystem metabolism. Estuar Coast Shelf Sci 60:673-694

Institute for Scientific Information (1998) Journal of citation report. Institute for Scientific Information, Philadelphia, PA

King DA (2004) The scientific impact of nations. Nature 340: 311-316

Kleypas JA, Buddemeier RW, Archer D, Gattuso JP, Langdon C, Opdyke BN (1999) Geochemical consequences of increased atmospheric $\mathrm{CO}_{2}$ on coral reefs. Science 284:118-120

MacDonald RW, Barrie LA, Bidleman TF, Diamond ML and 25 others (2000) Contaminants in the Canadian Arctic: 5 years of progress in understanding sources, occurrence and pathways. Sci Total Environ 254:93-234

Milliman JD, Droxler AW (1996) Neritic and pelagic carbonate sedimentation in the marine environment: ignorance is not bliss. Geol Rundsch 85:496-504

Nixon SW, Ammerman JW, Atkinson LP, Berounsky VM and 12 others (1996) The fate of nitrogen and phosphorus at the land-sea margin of the North Atlantic Ocean. Biogeochemistry 35:141-180

Pendelbury DA (1991) Science, citation, and funding. Science 251:1410-1411

Rabouille C, Mackenzie FT, Ver LM (2001) Influence of the human perturbation on carbon, nitrogen, and oxygen biogeochemical cycles in the global coastal ocean. Geochim Cosmochim Acta 65:3615-3641

Small C, Nicholls RJ (2003) A global analysis of human settlement in coastal zones. J Coast Res 19:584-599

Smith SV, Hollibaugh JT (1993) Coastal metabolism and the oceanic organic carbon balance. Rev Geophys 31:75-89

Valiela I, Bowen JL, York JK (2001) Mangrove forests: one of the world's threatened major tropical environments. BioScience 51:807-815

Vidal M, Duarte CM, Sanchez MC (1999) Coastal eutrophication research in Europe: progress and imbalances. Mar Pollut Bull 38:851-854

Wollast R (1998) Evaluation and comparison of the global carbon cycle in the coastal zone and in the open ocean. In: Brink KH, Robinson AR (eds) The sea. John Wiley \& Sons, New York, p 213-252

Submitted: August 25, 2004; Accepted: December 30, 2004

Proofs received from author(s): May 14, 2005 